\title{
A EDUCAÇÃO AMBIENTAL NAS PREFEITURAS MUNICIPAIS DO SUDOESTE DO PARANÁ
}

Aline Tonet $^{1}$

Berta Lúcia Pereira Villagra²

Resumo: $O$ presente artigo tem por finalidade sistematizar e discutir 0 levantamento de dados realizados sobre a educação ambiental nas Prefeituras Municipais do Sudoeste do Paraná. A EA se fundamenta como forma interativa de educação, ao possibilitar aos cidadãos, através de um processo participativo e permanente uma construção crítica e reflexiva sobre a problemática ambiental. A metodologia caracterizou-se pela revisão bibliográfica do tema geral e pelas entrevistas realizadas pela décima fase do curso de Licenciatura em Ciências Biológicas da Universidade Federal da Fronteira Sul em 2014. Os resultados das entrevistas possibilitaram a aproximação com os conceitos, documentos e contexto da área EA, além de favorecer a reflexão da prática docente no desenvolvimento interdisciplinar.

Palavras-chave: Educação Ambiental; Municípios; Paraná.

${ }^{1}$ Universidade Federal da Fronteira Sul, Chapecó, SC. E-mail: ali_tonet@hotmail.com

2 Universidade Federal da Fronteira Sul, Chapecó, SC. E-mail: berta.villagra@uffs.edu.br 


\section{Introdução}

A educação ambiental vem assumindo um importante papel no contexto em que vivemos marcados pelas discussões da degradação do meio ambiente. Estas degradações desencadearam em profundos impactos ambientais decorrentes da má utilização dos recursos naturais, não atingindo somente a alguns países, como também, o planeta como um todo.

A estas mudanças pode-se direcionar a postura histórica e cultural assumida pelo indivíduo, ao não se enxergar como parte do meio ambiente e por consequência utilizando-se dos recursos naturais sem nenhuma restrição estabelecida por critérios. E é justamente pela falta de limites que o surgimento de graves problemas ambientais emergiu pela escassez dos recursos naturais e pelo aumento da produção de resíduos provocando o que denominamos de crise ambiental (BRASIL, 2015).

A crise ambiental tomou maiores proporções com o processamento dos recursos naturais e geração de resíduos com a Revolução Industrial, o que aumentou significativamente: a migração da população do meio rural para meio urbano, desenvolvimento rápido da tecnologia e entre outros fatores. Em meio a estas preocupações, a proposta de Educação Ambiental (EA) surge como uma ferramenta a auxiliar a relações do homem com a natureza (BRASIL, 2015).

Segundo Jacobi (2003, p.190): "a educação ambiental é condição necessária para modificar um quadro de crescente degradação socioambiental', e salienta ainda como é importante construir sentidos e reflexões ao promover práticas sociais em Educação Ambiental.

Esse artigo busca ampliar o conhecimento das questões pertinentes à educação ambiental a partir de uma revisão bibliográfica dos conceitos e demonstrar quais e como estão sendo realizadas as ações de EA pelos municípios do Sudoeste do Paraná, analisando a influência desta no dia a dia dos cidadãos. Através de uma pesquisa qualitativa baseada na fundamentação teórica pesquisada em autores pertinentes ao assunto abordado e entrevistas com os representantes dos Municípios. É fato que o processo de Educação ambiental requer uma mudança no nosso comportamento, ou seja, um olhar diferenciado em buscar a sustentabilidade do planeta.

\section{O que é Educação Ambiental?}

A Educação Ambiental é um ramo da educação com objetivo de propagar o conhecimento e reflexão sobre o ambiente, como meio de auxiliar na preservação e utilização sustentável dos seus recursos. Este é um processo constante, em que os indivíduos e a comunidade assumem com consciência a importância do meio ambiente e adquirem conhecimentos, capacidades, experiências, valores e a determinação que os torna capazes de agir, individual ou coletivamente, na busca de soluções para os problemas ambientais (RIGONAT apud SILVA, 2012), a educação ambiental apresenta-se como um componente imprescindível para a sensibilização e mudanças de 
comportamento, e posteriori formação de sensu crítico e ou de valores (SILVA, 2012).

Ao indicar a EA, conforme Trevisol (2003, p.93), almeja-se que esta seja apropriada a conduzir os indivíduos a analisarem suas práticas, concepções e seus hábitos, acreditando desenvolver nas pessoas uma afinidade mais harmoniosa e sustentável com o meio em que estão inseridas.

O Programa Nacional de Educação Ambiental - ProNEA (2005) estabelece que a EA deve ser pautada em uma abordagem sistêmica, abrindose a integrar os variados aspectos desencadeados pela atual problemática ambiental. Segundo o documento ProNEA:

Reconhecer o conjunto das inter-relações e as múltiplas determinações dinâmicas entre os âmbitos naturais, culturais, históricos, sociais, econômicos e políticos. Mais até que uma abordagem sistêmica, a Educação Ambiental exige a perspectiva da complexidade, que implica em que no mundo interagem diferentes níveis da realidade (objetiva, física, abstrata, cultural, afetiva...) e se constroem diferentes olhares decorrentes das diferentes culturas e trajetórias individuais e coletivas (BRASÍLIA, 2005, p. 34).

A Secretaria de Educação continuada, Alfabetização e Diversidade em seu caderno intitulado Educação Ambiental: aprendizes de sustentabilidade de (2007) discute algumas das ideias do canadense Lucy Sauvé sobre a EA: Tratase de proporcionar a aquisição de conhecimentos e habilidades que fortaleçam a interação com o ambiente, baseando-se no compartilhamento de fatos, conteúdos e conceitos, tornando o meio ambiente um objeto de aprendizado, de modo que este, ofereça a educação ao ar livre com estratégia pedagógica que atendam a necessidade do contato com a natureza, ou seja, contexto físico, social e cultural em que envolve a escola e a comunidade. E que estes, em conjunto possam buscar de forma processual e participação ativa dos educandos que assim, possam aprender a resolver e prevenir os problemas ambientais, tomando o meio ambiente como uma meta de aprendizado (BRASÍLIA, 2007). Segundo Lei No: 9.795/1999 que institui a Política Nacional de Educação Ambiental, compreende como EA:

Art. 1ํ Entendem-se por Educação Ambiental os processos por meio dos quais o indivíduo e a coletividade constroem valores sociais, conhecimentos, habilidades, atitudes e competências voltadas para a conservação do meio ambiente, bem de uso comum do povo, essencial à sadia qualidade de vida e sua sustentabilidade (BRASIL, 1999)

As Diretrizes Curriculares Nacionais da Educação Ambiental direcionam a aspectos importantes no âmbito da educação, prevendo a Educação Ambiental 
com atividades sociais em que desenvolvam no sujeito percepções das "relações com a natureza e com os seres humanos", de modo que, possa evidenciar através das atividades humanas ações que contemplem a prática social e a ética ambiental (SILVA, 2012).

$\mathrm{Na}$ Carta de Belgrado, foi produzida no Encontro Internacional em Educação Ambiental, promovido pela UNESCO em Belgrado, lugoslávia (1975) teve como ponto principal tratar de medidas de crescimento econômico sem prejudicar ou diminuir as condições de vida dos indivíduos, como também de qualidade do meio ambiente. a carta apresenta uma proposta de reformas dos sistemas de educação priorizando a constatação de uma nova ética, foi por meio desta, que EA estabeleceu um relacionamento entre estudantes e professores, a escola e a comunidade e o sistema educacional e a sociedade (SILVA, 2012).

É por meio deste relacionamento que Carvalho (2008) salienta que a EA procura despertar sensibilidades afetivas e as capacidades cognitivas como forma de instigar e construir uma leitura de mundo baseada no desenvolvimento ambiental e sustentável. A autora ainda menciona, que ao propor a mediação entre as experiências do indivíduo e dos coletivos sociais é que se estabelecem as relações com o meio ambiente. É em meio a estas perspectivas que as ações do educador interferem no processo de ensino-aprendizagem construindo laços entre a sociedade e o ambiente e assim, facilitando o desenvolvimento social de novas sensibilidades, novos hábitos e postura, neste processo a EA se instrumentaliza como mediadora e interlocutora (CARVALHO, 2008).

Desta forma, a Educação Ambiental propicia a compreensão da natureza e sua complexidade ao interpretar a interdependência entre os distintos elementos que constituem o ambiente, como medida para usar racionalmente os recursos do meio para satisfazer necessidades materiais e espirituais da sociedade, no presente e no futuro (LEAO; SILVA, 1995).

Pois de fato, como o princípio 4 do Tratado de Educação Ambiental para Sociedades Sustentáveis e Responsabilidade Social (BRASIL, 1992, p.2) menciona: "A Educação Ambiental não é neutra, mas ideológica. É um ato político, baseado em valores para a transformação social".

\section{Educação Ambiental no Paraná}

O Estado do Paraná publicou em 11 de Janeiro de 2013 o primeiro documento que institui uma Política Estadual de Educação Ambiental, garantindo por meio do Art. $3^{\circ}$ que todos têm direito a um ambiente ecologicamente equilibrado, mas com o compromisso de promover a sustentabilidade, respeitando todas as formas de manifestação da vida (PARANÁ, 2013).

Segundo o Art. $2^{\circ}$ das Políticas Estadual de Educação Ambiental no contemplando todos os níveis e modalidades de ensino seja ela formal ou não, 
em que as práticas dos indivíduos, tanto em sua individualidade como na formação do coletivo, possam estabelecer meios de fortalecer seus conhecimentos e exercícios de cidadania ao se comprometer com todas as dimensões sejam elas: de preservação, conservação ou recuperação do meio ambiente e da qualidade de vida (PARANÁ, 2013).

Através do Art. 6o foi instituído também o Sistema Estadual de Educação Ambiental com intuito de:

Art. 6ำ (...) § 1ㅇ O Sistema Estadual de Educação Ambiental será implantado com a finalidade de integrar, sistematizar e difundir informações e experiências, programas, projetos e ações, bem como realizar diagnósticos, estabelecer indicadores e avaliar a política de Educação Ambiental no Estado do Paraná (PARANÁ, 2013).

Nesse contexto, segundo (REIGOTA apud JACOBI, 2003), a Educação Ambiental direciona suas propostas a ações pedagógicas baseando-se na conscientização, mudança de hábito, desenvolvimento de competências, capacidade de analisar, diagnosticar e efetivar a participação dos educandos neste processo.

Deste modo, (PÁDUA; TABANEZ apud JACOBI, 2003), a Educação Ambiental proporciona uma amplificação dos conhecimentos, mudança de valores e aprimoramento de habilidades, condições fundamentais para instaurar maior integração e harmonia dos sujeitos com o meio ambiente.

E de fato as políticas ambientais e os programas educativos vêm fortalecendo o processo de conscientização da crise ambiental promovendo em análise o aumento da demanda ao desenvolver novos enfoques de integração de uma realidade que não seja contraditória e ao mesmo tempo, geradora de desigualdades, ao proporcionar medidas que vão além da mera aplicação dos conhecimentos científicos e tecnológicos (JACOBI, 2003).

E ai vem o desafio de traçar metas e construir uma educação ambiental que seja crítica e inovadora, em todos os níveis. Em que o seu enfoque esteja no direcionamento das perspectivas de ação, que integra o homem, natureza e o universo, considerando que os recursos naturais se esgotam e nós somos os principais responsáveis por sua degradação (JACOBI, 2003).

Segundo a notícia publicada pelo Governo do Estado do Paraná em 2014, em conformidade com a Política Estadual de Educação Ambiental e Sistema Estadual de Educação Ambiental Lei 17.505/2013, foi incorporado nos currículos escolares de escolas públicas e particulares do Paraná o ensino de Educação Ambiental através de projeto pedagógico, o tema abordado que constitui a unidade de atuação das escolas foram as Bacias Hidrográficas onde se inserem, meio ambiente e sustentabilidade que são temas que já estão inseridos e constituem o dia a dia nas escolas (PARANÁ, 2013). 


\section{Metodologia}

A presente pesquisa foi desenvolvida como uma das propostas de atividade do componente curricular Tópicos em Educação Ambiental, ofertado a décima fase do curso de Licenciatura em Ciências Biológicas da Universidade Federal da Fronteira Sul, sob a orientação da professora Dra Berta Lúcia Pereira Villagra.

Após discussões em sala sobre práticas de Educação Ambiental nos municípios da região no sudoeste do Paraná foram levantados os municípios com possibilidade de entrevista (Anexo 1) através de e-mails, telefonemas, visitas e conversas com responsáveis pelas secretarias de meio ambiente. A prática abrangeu a Microrregião de Capanema, Francisco Beltrão e Pato Branco com a coleta de dados no período de novembro e dezembro de 2014 pelos discentes.

As informações foram parcialmente apresentadas e discutidas em sala de aula através de seminários. A partir dos dados levantados foram desenvolvidos gráficos e tabelas para compilação da totalidade dos municípios, procedendo-se a discussão. Dos 19 municípios listados na (Tabela 1), conseguiu-se obter contato e levantar informações de 10 municípios do sudoeste do Paraná com relação às atividades de Educação Ambiental.

Tabela 1: Lista de municípios das Microrregiões investigados sobre práticas de Educação Ambiental do Paraná.

\begin{tabular}{|c|c|c|}
\hline \multicolumn{3}{|c|}{ Municípios de abrangência da pesquisa } \\
\hline Mesorregião & Microrregião & Municípios \\
\hline \multirow{3}{*}{$\begin{array}{c}\text { Mesorregião Sudoeste } \\
\text { Paranaense }\end{array}$} & Microrregião de Capanema & $\begin{array}{l}\text { Ampére } \\
\text { Bela Vista da Caroba } \\
\text { Capanema } \\
\text { Pérola D'Oeste } \\
\text { Planalto } \\
\text { Pranchita } \\
\text { Realeza } \\
\text { Santa Isabel do Oeste }\end{array}$ \\
\hline & $\begin{array}{l}\text { Microrregião de Francisco } \\
\text { Beltrão }\end{array}$ & $\begin{array}{l}\text { Barracão } \\
\text { Boa Esperança do Iguaçu } \\
\text { Dois Vizinhos } \\
\text { Francisco Beltrão } \\
\text { Nova Esperança do Sudoeste } \\
\text { Nova Prata do Iguaçu } \\
\text { Salgado Filho } \\
\text { Salto do Lontra } \\
\text { Santo Antonio do Sudoeste }\end{array}$ \\
\hline & Microrregião de Pato Branco & $\begin{array}{l}\text { Coronel Vivida } \\
\text { Pato Branco }\end{array}$ \\
\hline
\end{tabular}

Revbea, São Paulo, V.11, № 2: 299-312, 2016. 
A metodologia foi norteada inicialmente pela pesquisa bibliográfica através de opção de artigos, livros, documentos e publicação de entidades ambientais, que fundamentassem a Educação Ambiental em relação às práticas de acordo com tema proposto.

As consultas aconteceram por meio de entrevistas para levantar dados guiados pela pesquisa de campo de natureza quantitativa focalizando aspectos de objetividade (FONSECA apud GERHARDT; SILVEIRA, 2009), expressando em números opiniões e informações para classificá-las e analisá-las (MINAYO apud ALMEIDA, 2012), sobre os processos de desenvolvimentos de ações em EA através das Prefeituras Municipais, sendo essenciais para analisar os meios pelos quais são organizadas estas atividades e sua repercussão na aplicação da prática nas comunidades.

Segundo Gerhardt e Silveira (2009) a pesquisa de campo com levantamento de dados apresenta entre suas vantagens o conhecimento direto da realidade, com agilidade na obtenção de informação agrupada em tabelas que permitem uma riqueza na análise estatística.

Os cursos de graduação em Licenciatura que envolvem educação ambiental também fazem parte ao contribuir com atividades e ou eventos, ainda que no levantamento deste não foi possível a inserção dos projetos de extensão, estágios e projeto integradores de disciplinas que envolvam a comunidade.

\section{Resultados}

Foram levantados dados sobre a prática educacional de Educação Ambiental em 10 municípios investigados, sendo eles: Ampére, Bela Vista da Caroba, Boa Esperança do Iguaçu, Coronel Vivida, Francisco Beltrão, Pato Branco, Pérola D' Oeste, Realeza, Salto do Lontra e Santo Antônio do Sudoeste, todos se pronunciaram afirmando positivamente haver o desenvolvimento de atividades na área ambiental.

Durante as entrevistas pode-se destacar que as atividades de Educação Ambiental desenvolvidas em todos os municípios foram os debates e conversas e projetos. Outra atividade apontada com maior frequência foi às datas comemorativas como dia da Água, dia do Rio, dia da Árvore, dia Mundial do Meio Ambiente em seis municípios e as campanhas e palestras tais como: separação do lixo, reciclagem e recolhimento do lixo (Figura 1). Percebe-se um grande empenho dos secretários de meio ambiente em possibilitar os acessos a EA como ferramentas no estímulo a novos conhecimentos, no processo de sensibilização e nas mudanças de comportamento. 


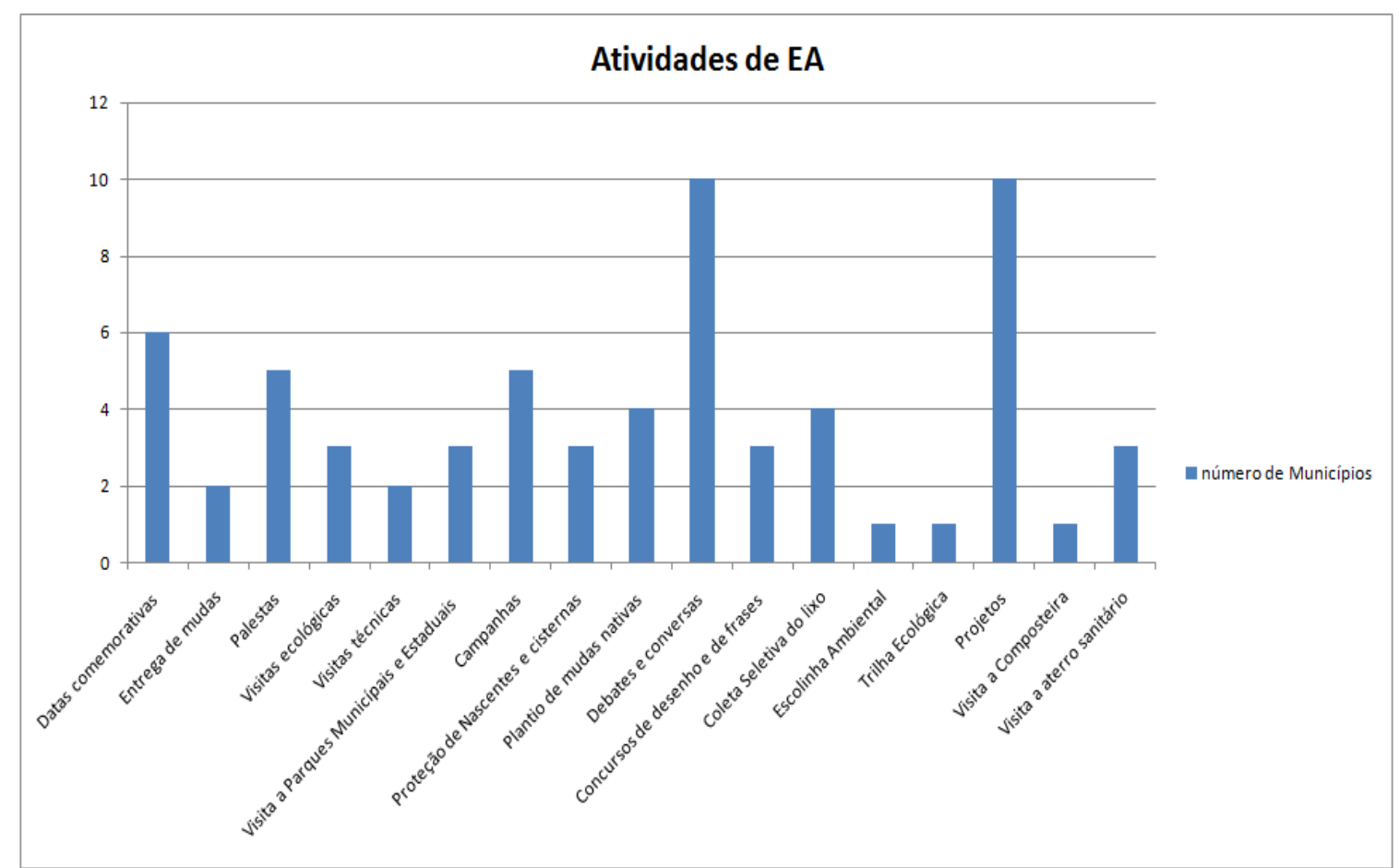

Figura 1: Frequência de atividades de EA desenvolvidas nos municípios do Sudoeste do Paraná.

Os trabalhos nos municípios sobre a educação ambiental são coordenados pelas Secretárias Municipais de Meio Ambiente, representada pelos secretários ou responsáveis deste setor, alguns municípios contam ainda com as contribuições de outros profissionais como engenheiros florestal, ambiental, etc. Sendo realizado em parcerias com as escolas municipais e estaduais do município, Instituto Ambiental do Paraná, parques, Emater, sindicatos e em colaboração com as demais Secretárias Municipais.

Segundo os secretários de Meio Ambiente ou responsável as atividades de Educação Ambiental são direcionadas em geral às escolas, mas são também, desenvolvidas com as comunidades urbanas e rurais, como por exemplo, com os agricultores e nos Clubes de Mães no Município de Boa Esperança do Iguaçu.

$\mathrm{Na}$ Figura 2 foram sistematizados os apontamentos dos entrevistados em relação aos grupos, os quais participam das atividades de EA ofertadas pelos Municípios. 


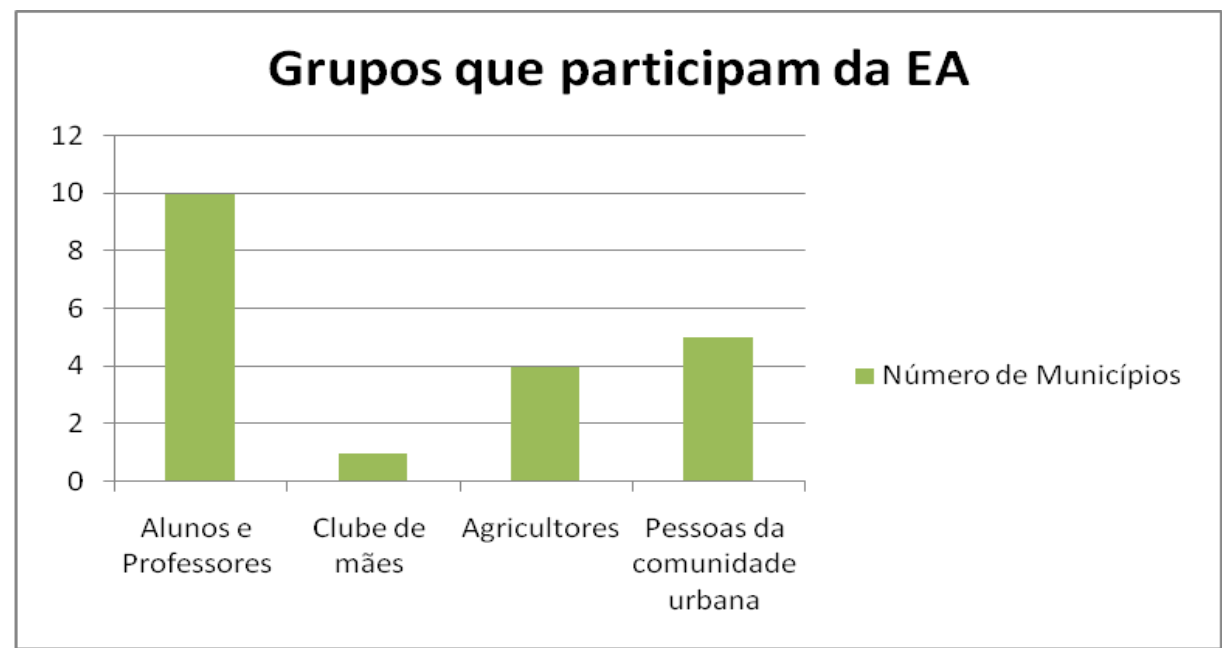

Figura 2: Grupos participantes das práticas de EA ofertadas nos Municípios.

Segundo as entrevistas, as atividades desenvolvidas são permanentes e diversificadas. Estes ainda salientam a importância de Educação Ambiental, mencionando o quanto estas atividades melhoram o processo de sensibilização como comenta o responsável do município de Boa Esperança do Iguaçu: (...) a mudança de comportamento de todos para amenizar os estragos já causados, evitar novos e maiores danos ao ambiente, se faz necessário para educar desde cedo para que $o$ aprendizado se efetive (...).

As atividades de EA apontadas pelos entrevistados em que obtiveram retorno de alguma forma foram: coleta seletiva do lixo (38\%), proteção de fontes $(29 \%)$, plantio de mudas (19\%), reciclagem de lixo (9\%) e escolinha ambiental $(5 \%)$. Essas práticas tiveram seus objetivos alcançados a partir das pequenas mudanças de atitudes dos participantes ao perceber a responsabilidade e comprometimento destes com as atividades, além da aparência dos ambientes em que foram alvo (Figura 3).

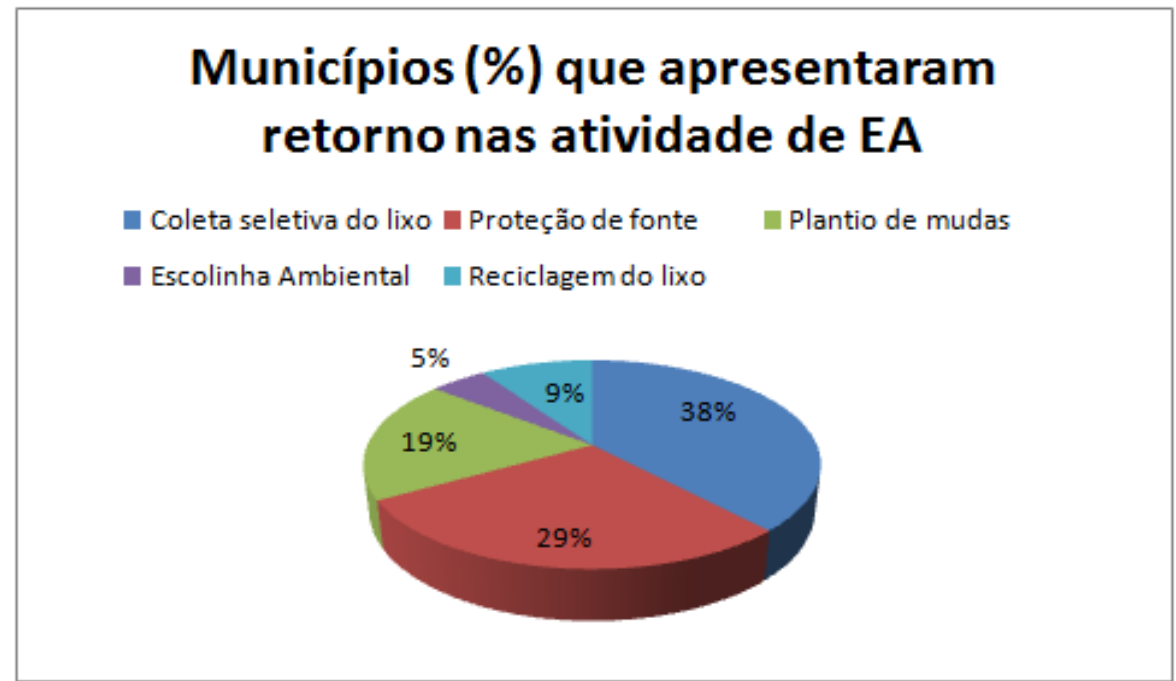

Figura 3: Atividades de EA em que os objetivos dos Municípios foram alcançados. 
Sendo também foram realizados de forma processual e constante, em que compreenderam a importância destas ações no meio social e principalmente ambiental.

A Figura 4, de acordo com os dados levantados nos 10 municípios entrevistados todos eles, apontaram desenvolver atividades e projetos nos espaços da escola (33\%), mas também em áreas de contato com a natureza como áreas verdes, parques, bosques municipais e propriedades rurais.

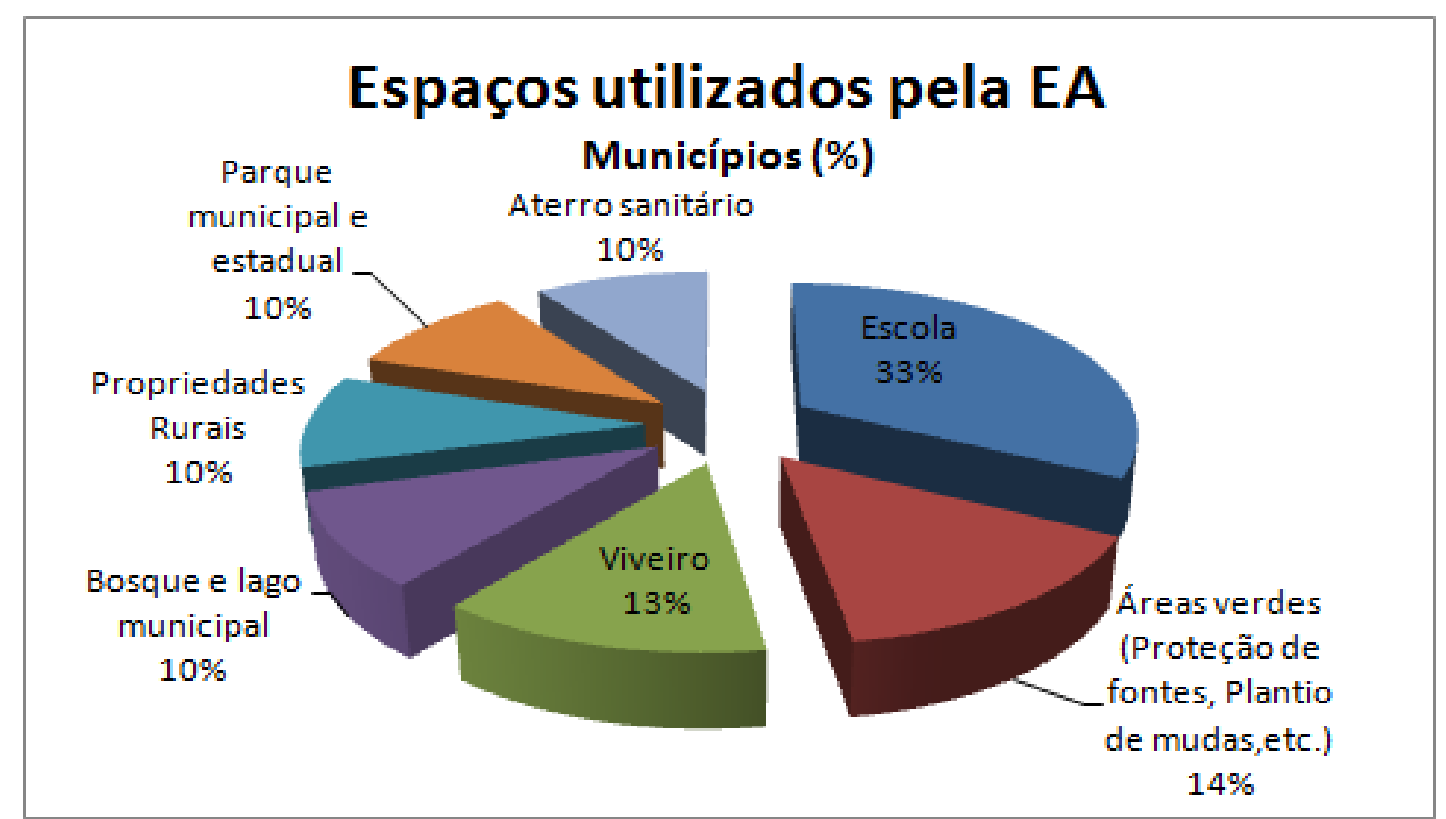

Figura 4: Ambientes usados pelos Municípios para a realização das ações de EA no sudoeste do Paraná.

\section{Discussões dos resultados}

Os resultados da presente pesquisa permitiram diagnosticar importância de buscar alternativas para o trabalho com a educação ambiental ao proporcionar um trabalho multidisciplinar, demonstrando que as Prefeituras Municipais estão procurando desenvolver, com os recursos disponíveis um aprendizado que através de pequenas intervenções possam envolver atividades de descontração, e ao mesmo momento, procuram integrar conhecimentos e habilidades (SANTOS, 2009).

Dos municípios investigados todos elencaram a escola como espaços utilizados na realização de atividades de EA. Segundo Reigota (apud BARCELOS, 2008) a escola é um local privilegiado para a realização da educação ambiental, pois ao desenvolver a oportunidade da criatividade, oferece diferentes estratégias, que são eficientes para sensibilizar os discentes. Esta sensibilização se estende a comunidade escolar de modo geral, ao pensar em novas iniciativas que transcendam este ambiente (SANTOS, 2009). 
Como dispõe o Plano Nacional de Educação Ambiental na Lei 9795/99 sobre os currículos escolares em relação à Educação Ambiental, esta não deve se caracterizar como uma disciplina, mas sim, como tema que permite estabelecer relações com as atividades escolares e assim dimensionar a temática ao desenvolver-se de maneira interdisciplinar. Neste processo, a EA deve estar presente no currículo que permeia todas as disciplinas, pois possibilita estabelecer questões pontuais entre a humanidade, o meio natural em que está inserido e as relações sociais sem deixar de considerar suas especificidades (VIEIRA, 2008).

Atualmente no Senado Federal tramita o Projeto de Lei no 221 de 2015, que prevê a alteração da a Lei no 9.795/99, que dispõe sobre a educação ambiental, institui a Política Nacional de Educação Ambiental, estabelece como objetivo fundamental na $E A$, a promoção de ações que estimulem o uso sustentável dos recursos naturais e a EA como disciplina específica nos níveis de ensino fundamental e médio (BRASIL, 2016).

Para Moreira (apud VIEIRA, 2008) "nas escolas não se aprendem apenas conteúdos sobre o mundo natural e social; adquirem-se também consciência, disposições e sensibilidades que comandam relações e comportamentos sociais do sujeito que estrutura sua personalidade". Desta forma, a interdisciplinaridade vai muito além da integração entre as disciplinas, pois esta necessita atribuir significado que envolve o conhecimento do cotidiano dos alunos visto os ambientes escolares e áreas naturais que foram desenvolvidas as atividades nos municípios do sudoeste do Paraná, para que se permita refletir sobre questões atuais e construir um mundo em que se deseja viver.

E se tratando da região sudoeste do Paraná, o que se observa é que muitas das atividades de EA estão centradas nas escolas e em seus atores como principais mediadores neste processo de sensibilização perante os problemas ambientais da degradação dos recursos naturais e que bom que a educação, esteja entre os principais meios para se transformar essa situação.

Sacristán (apud VIEIRA, 2008) compreende o currículo como um processo que constitui o entrelaçamento de influências com campos que priorizam as atividades diferenciadas e inter-relacionadas, o que permite analisar e significar o curso de objetivação e concretização do currículo em seus vários níveis, sem deixar de evidenciar suas múltiplas transformações, que viabiliza a educação ambiental na escola.

Os pontos positivos perceptíveis através da coleta de dados, é que os municípios apresentaram algum tipo de atividade de EA em constante processo de construção e desenvolvimento. E que mesmo, envolvendo os alunos e professores em geral nas atividades, proporcionam projetos e campanhas com grupos da comunidade externa da escola.

Ainda pode-se observar que a Educação Ambiental tem criado vínculos de inserção na sociedade por meio de programas e projetos direcionados Revbea, São Paulo, V.11, № 2: 299-312, 2016.

revista brasileira educação ambiental 
principalmente as escolas que se apoiam nas ações isoladas e campanhas realizadas pelas datas comemorativas desempenhadas pelos professores com os alunos. Resultado semelhante foi comumente encontrado por (GUIMARAES, 2004; LEME, 2006; CASCINO, 2007 apud XAVIER, 2015).

\section{Considerações finais}

É fato, que mesmo com tantos encontros internacionais, com acordos, leis e tratados, dispõe-se ainda, de um número muito pequeno de países que efetivamente desenvolvem práticas de Educação Ambiental para melhorar as questões ambientais pertinentes a sua realidade.

De fato, a Educação Ambiental é um processo longo e minucioso, no sentido de, que requer um cuidado e constante persistência que gradualmente sensibiliza os indivíduos. Mudanças de comportamentos e atitudes são de fundamental importância para que cada um contribuindo com uma fração reconheça o seu papel enquanto cidadão, de cuidar e respeitar o ambiente em que vive e do qual depende para sobreviver.

O Estado do Paraná, somente a partir de 2013 constituiu políticas públicas de Educação Ambiental no estado, regulamentando as realidades pertinentes a cada situação vivenciadas por cada região e sistematizando como a EA será desenvolvida em cada nível.

É evidente, que a muito o se fazer pela Educação ambiental no estado, e o que se observa é que os municípios venham realizando um fundamental papel neste processo, mesmo que aos poucos procuram utilizar a melhor forma os recursos disponíveis para explorar meios de ação para Educação ambiental.

\section{Referências}

ALMEIDA, O.S.; et al. Educação Ambiental e a prática educativa: estudo em uma escola estadual de Divisa Alegre - MG. Revista Metáfora Educacional (ISSN 1809-2705) - versão on-line, n. 13 (jul. - dez. 2012), Feira de Santana BA (Brasil), dez./2012. p. 155-173. Disponível em:< http://www.valdeci.bio.br/revista.html>. Acesso em: 23 abr, 2015.

BARCELOS, V. Educação Ambiental: sobre princípios, metodologias e atitudes. Rio de Janeiro: Vozes, 2008, 195p.

BRASIL. Programa de Gestão Ambiental. Ministério Público Federal. O que é a Educação Ambiental. Disponível em: < http://pga.pgr.mpf.mp.br/pga/educacaoambiental>. Acesso em: 04 abr. 2015. 
BRASIL. Tratado de Educação para Sociedades Sustentáveis e Responsabilidade Global. Associação Portuguesa de Educação Ambiental ASPEA. Rio de Janeiro, 1992. Disponível em: < http://www.aspea.org/TratadoEducAmbientInt7Abr.pdf>. Acesso em: 13/04/15.

BRASIL. Lei no LEI No 9.795, de 27 de abril de 1999. Política Nacional de Educação Ambiental.

Disponível

em: <http://www.planalto.gov.br/ccivil 03/leis/19795.htm>. Acesso em: 15 mar. 2015.

BRASÍLIA. Educação Ambiental: aprendizes de sustentabilidade. Secretário de Educação Continuada, Alfabetização e Diversidade. Brasília, 2007. Disponível em:< http://portal.mec.gov.br/dmdocuments/publicaca02.pdf $>$. Acesso em: 11/04/15.

BRASÍLIA. PRONEA. Programa Nacional de Educação Ambiental. 2005. Disponível em: $<$ http://portal.mec.gov.br/secad/arquivos/pdf/educacaoambiental/pronea3.pdf>. Acesso em: 11/04/15.

CARVALHO, I.C.M. 3.ed. Educação Ambiental: a formação do sujeito ecológico. 3.ed. São Paulo. Cortez. 2008.

GERHARDT, T.E.; SILVEIRA, D.T. Métodos de pesquisa / [organizado por] Tatiana Engel Gerhardt e Denise Tolfo Silveira; coordenado pela Universidade Aberta do Brasil - UAB/UFRGS e pelo Curso de Graduação Tecnológica Planejamento e Gestão para o Desenvolvimento Rural da SEAD/UFRGS. Porto Alegre: Editora da UFRGS, 2009. Disponível em:< http://portal.mec.gov.br/dmdocuments/publicacao2.pdf>. Acesso em: 23/04/15.

JACOBI, P. EDUCAÇÃO AMBIENTAL, CIDADANIA E SUSTENTABILIDADE. Scielo, São Paulo, v. 118, n. , p.189-205, mar. 2003. Disponível em: $<$ http://www.scielo.br/pdf/cp/n118/16834.pdf>. Acesso em: 14 abr. 2015.

LEÃO, A.L.C.; SILVA, L.M.A. Fazendo Educação Ambiental. Recife: $\mathrm{CPRH}$, 1995.

PARANÁ. Lei oㅡ 17505, de 11 de janeiro de 2013. Política Estadual de Educação Ambiental e 0 Sistema de Educação Ambiental. Curitiba, PR: Diário Oficial, 11 jan. 2013. n. 8875. Disponível em: < http://www.legislacao.pr.gov.br/legislacao/listarAtosAno.do?action=exibir\&codAto $=85172 \&$ indice $=1 \&$ total Registros $=57 \&$ anoSpan $=2013 \&$ anoSelecionado $=2013 \& \mathrm{~m}$ esSelecionado=0\&isPaginado=true $>$. Acesso em: 23 mar. 2015.

PARANÁ. Agências de Notícias do Paraná. Educação Ambiental será incluída no currículo das escolas do Paraná em 2014. 2013. Disponível em: $<$ http://www.aen.pr.gov.br/modules/noticias/article.php?storyid=77915>. Acesso em: 05 abr. 2015.

TREVISOL, J.V. A educação em uma sociedade de risco: tarefas e desafios na construção da sustentabilidade. Joaçaba: UNOESC, 2003.

SANTOS, L.M.M. A importância de práticas de ensino criativas na Educação Ambiental. In: ENCONTRO NACIONAL DE PESQUISA EM EDUCAÇÃO EM 
CIÊNCIAS, 7., 2009, Florianópolis. Anais... Florianópolis: Issn, 2009. p. 1 - 9. Disponível em: <http://posgrad.fae.ufmg.br/posgrad/viienpec/pdfs/101.pdf>. Acesso em: 23 abr. 2015.

SILVA, D.G. A importância da Educação Ambiental para a sustentabilidade. 2012. 11 f. TCC (Graduação) - Curso de Ciências Biológicas Com ênfase em Gestão Ambiental, Faculdade Estadual de Educação, Ciências e Letras de Paranavaí, São Joaquim, 2012. Disponível em: $<$ http://www.uniedu.sed.sc.gov.br/wp-content/uploads/2014/04/DANISEGUIMARAES-DA-SILVA.pdf>. Acesso em: 14 mar. 2015.

VIEIRA, Suzane da Rocha. A educação ambiental e o currículo escolar. Revista Espaço Academico, Santa Catarina, v. 7, n. 83, p.1-1, abr. 2008. Mensal. Disponível em: <http://www.espacoacademico.com.br/083/83vieira.htm>. Acesso em: 05 jun. 2016.

XAVIER, M.A. Oficinas de Educação Ambiental: contribuição à educação continuada dos professores do Município de Luiz Eduardo Magalhães-BA / Márcia Andaluza Xavier. - Luiz Eduardo Magalhães/BA, 2008. Disponível em: $<$ http://www.linagalvani.org.br/pdfs/oficinas-de-educacao-ambiental.pdf >. Acesso em 27 abr, 2015.

\section{ANEXO 1}

Modelo de questionário usado para as entrevistas:

Bom tarde!

Sou acadêmica do $10^{\circ}$ período do curso de Licenciatura em Ciências Biológicas da Universidade Federal da Fronteira Sul (UFFS), Campus Realeza/PR e estou cursando neste semestre o Componente Curricular "Tópicos em Educação Ambiental". Assim, venho por meio deste, buscar compreender sobre como funciona as atividades de Educação Ambiental desenvolvidas no Município (nome do município) e para isso foi elaborado alguns questionamentos:

- Há Educação Ambiental no Município? Se não, há interesse em desenvolver projetos e programas?

- Como é? Quem faz? É em grupo? É permanente? Para quem? É importante? Já houve retorno de algum projeto? Onde acontece, em área verde, dentro de salas? Etc.

Desde já agradeço pela colaboração e aguardo respostas.

Att,

(Nome do Acadêmico)

Acadêmica de Ciências Biológicas

Universidade Federal da Fronteira Sul

Campus Realeza - PR

(e-mail do acadêmico) 